\title{
Retrospective Analysis of the Black Sea Thermohaline Fields on the Basis of Empirical Orthogonal Functions
}

\author{
V. N. Belokopytov \\ Marine Hydrophysical Institute, Russian Academy of Science, Sevastopol, Russian Federation \\ e-mail: v.belokopytov@gmail.com
}

\begin{abstract}
Mathematical method combining optimal interpolation and expansion into the empirical orthogonal functions is developed to implement a retrospective analysis of the Black Sea thermohaline structure using incomplete archival oceanographic data. In order to increase spatial consistency of the resulted hydrologic structure, the earlier applied reconstruction method based on the horizontal empirical orthogonal functions was transformed to the combined one in which the vertical empirical orthogonal functions were the basic elements. The results of computing experiments make it possible to limit the number of the modes by 5 both for horizontal and vertical empirical orthogonal functions. Such a combination significantly reduces the calculation time and lowers the error level. This method was applied to reconstruct the monthly fields (spatial resolution is $10^{\prime}$ latitude $\times 15^{\prime}$ longitude) for almost a hundred-year period from 1923-2015. The relative part of the monthly average fields' successful reconstruction constitutes about $70 \%$. Based on the reanalysis data, the temperature and salinity climatic fields were calculated by various methods both for the entire observational period and for certain decades. It is revealed that in the XX century the gain-phase climatic characteristics of the Black Sea remain very stable whereas general tendencies in the long-term variations of the temperature and salinity seasonal cycles are opposite: when the sea temperature seasonal range rises the phase of annual harmonic of seasonal oscillations diminishes, and in the case of salinity, it increases, i. e. the salt content maximum shifts for the later period. The reanalysis data were used to study various aspects of the inter-annual and inter-decadal variability of the Black Sea thermohaline structure, density stratification, geostrophic circulation etc. The future trends imply application of the thermohaline fields' reanalysis array for studying long-term changes in the Black Sea basin as well as for assimilating observational data in the hydrophysical fields' reconstructions by the hydrodanamic models.
\end{abstract}

Keywords: Black Sea, thermohaline structure, reanalysis, climate, empirical orthogonal functions.

Acknowledgements: the investigation is carried out within the framework of the state task on the theme № 0827-2018-0001 "Fundamental studies of the interaction processes in the ocean-atmosphere system conditioning the regional spatial-temporal variability of natural environment and climate" (code "Ocean and atmosphere interaction”).

For citation: Belokopytov, V.N., 2018. Retrospective Analysis of the Black Sea Thermohaline Fields on the Basis of Empirical Orthogonal Functions. Physical Oceanography, [e-journal] 25(5), pp. 380389. doi:10.22449/1573-160X-2018-5-380-389

DOI: $10.22449 / 1573-160 X-2018-4-380-389$

(C) 2018, V. N. Belokopytov

(C) 2018, Physical Oceanography

Introduction. Along with the widespread arrays of atmospheric field global reanalysis, climate studies now began to use similar arrays of oceanographic characteristics such as ECWMF-Ocean, NCEP/GODAS, GECCO, SODA, Mercator, etc. A number of regional arrays of the Black Sea hydrophysical field reanalysis, belonging to different historical periods, was created in Marine Hydrophysical Institute of RAS [1-4]. 
The main method of the ocean retrospective analysis is an application of complete hydrodynamic models and methods of data assimilation of contact and remote observations. Alternative approach consists in the reconstruction of oceanographic fields by mathematical methods based on the statistical data structure only. Such technique, substantiated in the works of L. S. Handin, V. I. Belyaev and I. E. Timchenko [5-8], is applied in modern works [9-17], including the research [18] focused on the Black Sea. Despite various drawbacks of statistical methods, (in particular, a strong dependence on the spatial data structure) they can be used for studying long historical periods with more predictable level of reconstruction errors (degree of uncertainty) than when using hydrodynamic models. This is due to the fact that the modeling results are affected by not only the number and spatial distribution of the assimilated data, but also the quality of the applied atmospheric reanalysis. Recently, atmospheric arrays covering the entire XX century (ERA-20C, NOAA 20CR) have appeared, but it is still difficult to assess how much they take into account the systematic changes that have occurred in the global meteorological observation system over 100 years.

The purpose of the study was to make the Black Sea reanalysis array over the entire time interval of oceanographic observations covering 100 -year period, and to calculate climatic characteristics for various historical periods based on statistical methods for the reconstruction of thermohaline fields.

Methodology for carrying out the retrospective analysis. The calculation of reanalysis array was performed in several stages. At the first stage the primary data, which passed the quality check, were interpolated by the optimal interpolation method onto a regular grid. At the second stage the interpolated values were decomposed into empirical orthogonal functions (EOF). At the third stage the EOF temporal coefficients were calculated for the entire period of observations. At the fourth step monthly average thermohaline fields for the entire volume of the sea were reconstructed by the EOF temporal coefficients and were checked for compliance with predetermined statistical criteria.

Optimal interpolation method applied at the first stage is traditionally used in hydrometeorology as it provides taking into account the real correlation structure of the fields, to minimizing the interpolation error and providing its quantitative assessment. The equivalent of optimal interpolation is the variational inverse method, which, in particular, was applied in MEDATLAS for the Mediterranean and the Black Sea [19].

In this work, the system of equations of optimal interpolation [5] was solved by the Gaussian elimination. The measure of observation error was estimated as

$$
\eta_{i}=\sigma_{f}^{2} / \bar{x}_{i}{ }^{2}
$$

where $\sigma_{f}^{2}$ is an average dispersion of observation error equal to the sum of instrumental error and the variance of mesoscale variability (from [20, p. 150]);

\footnotetext{
$\overline{x^{\prime 2}}$ is an average dispersion of anomalies (deviations of $x_{i}$ values from the norm $\bar{x}$ at the observation point $i$ ). Climatic monthly average fields of temperature and salinity were used as the norm.
} 
It was assumed that the spatial correlation functions in the Black Sea are isotropic [21, 22]. For the autocorrelation function in the system of equations of optimal interpolation, an approximation [21], approximating the structure of Gaussian fields, was applied.

Primary interpolation on a regular grid was deliberately carried out in such a way as to prevent extrapolation when filling in free space, since the following steps were intended for this. As a result of the calculations, the arrays of interpolated values for 1910-2015 observation period with temporal resolution of 10 days and 1 month and $10^{\prime} \times 15^{\prime}$ spatial resolution were formed. Relative portion of the sea area coverage (Fig. 1) with data is maximal for the period of late 1950s early 1990s (up to $80 \%$ ) and is minimal in 1930-1940 and after 1995 (less than $20 \%)$.

At the second stage, the total correlation (autocovariance) matrix was calculated first

$$
\boldsymbol{C}=\operatorname{Cov}\left(\boldsymbol{x}^{\prime}, \boldsymbol{x}^{\prime}\right)
$$

over the entire set of fields of monthly average anomalies $\boldsymbol{x}^{\prime}$ from the optimal interpolation array. The covariance matrices $C$ calculated for each horizon were smoothed by three-point Shapiro filter. Then, a problem of finding eigenvalues and vectors was solved for $\boldsymbol{C}$ :

$$
\boldsymbol{C}=\boldsymbol{E} \boldsymbol{\Lambda} \boldsymbol{E}^{\mathrm{T}},
$$

where $\boldsymbol{E}$ is a matrix of eigenvectors; $\boldsymbol{\Lambda}$ is a diagonal matrix of eigenvalues; $\boldsymbol{E}^{\mathrm{T}}$ is transposed $\boldsymbol{E}$.

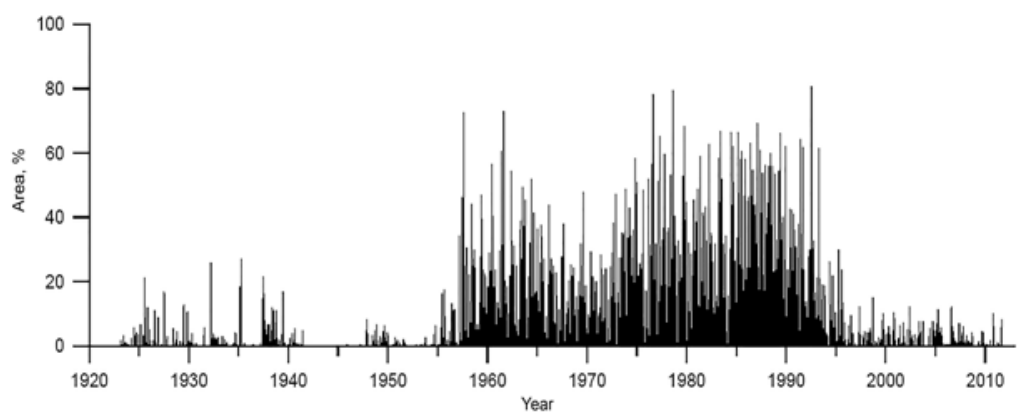

Fig. 1. Relative portion of the Black Sea area covered by the decade-derived values (regular grid) calculated by the method of optimal interpolation

The search for eigenvectors $\boldsymbol{E}$ was performed using $Q L / Q R$ decomposition algorithms, which are sufficiently effective for calculations [23, 24].

At the third stage, for each time moment temporal coefficients were calculated for all the EOF modes

$$
\alpha_{t i}=\boldsymbol{x}_{t}^{\prime} \boldsymbol{e}^{i},
$$

$\boldsymbol{e}^{i}$ is an eigenvector for the $i$-th mode; $\boldsymbol{x}_{t}^{\prime}$ is a field of monthly average anomalies in time moment $t$.

Due to the presence of gaps in $\boldsymbol{x}_{t}{ }_{t}$ fields, temporal coefficients were determined similarly to the least squares method [25, p. 14]: 


$$
\hat{\alpha}_{i}=\frac{\sum j \in \mathrm{K} x{ }_{j} e_{j}^{i}}{\sum j \in \mathrm{K}\left|e_{j}^{i}\right|^{2}},
$$

where $\mathrm{K}=\left\{j: x_{j}^{\prime}\right.$ are non-missing data $\} ;{ }^{\wedge}$ is a symbol of statistic assessment.

At the last stage the resulting fields were reconstructed in all grid nodes by the inverse procedure:

$$
\boldsymbol{x}_{t}^{\prime}=\sum_{i=1}^{M} \hat{\alpha}_{t i} \boldsymbol{e}^{i},
$$

where $M$ is a number of senior modes involved into the calculation.

When analyzing the results of reconstruction it turned out that this approach, previously used for surface fields, is poorly suited for three-dimensional thermohaline structure reconstruction [23]. When increasing the amount of applied modes (up to 20), the range of interannual anomalies increased excessively, the vertical structure of the fields was distorted by strong inversions. With a decrease in the number of modes, the spatial structure of anomalies significantly changed in comparison with the initial fields.

Errors in the sign and absolute magnitude of interannual anomalies are mainly related to the dependence of the assessment of $\hat{\alpha}_{t i}$ temporal coefficients on the initial data spatial distribution. Artificial vertical inversions often occur at the depth data non-uniform coverage. Therefore, in order to increase vertical and horizontal spatial consistency of the thermohaline structure, the reconstruction method was modified by connecting a block of vertical EOF.

Modified method is generally similar to the above-described one, which uses a set of horizontal EOF, but at the same time it has significant differences.

At the first stage vertical EOF $\boldsymbol{\Psi}$, calculated by the initial vectors $\boldsymbol{x}_{t}^{\prime}$ in the form of anomalies from monthly average climate vertical profile in the grid node, become the basic elements. The distribution of the first five vertical EOF of salinity is represented in Fig. 2.

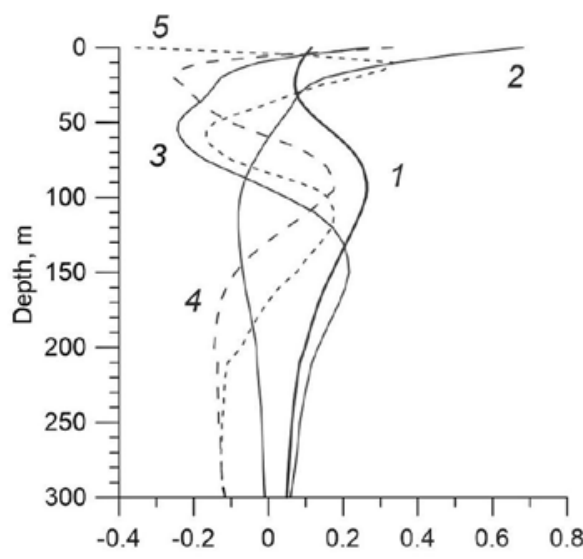

Fig. 2. Vertical EOF of salinity, figures denote the mode numbers 
Then the series of vertical EOF temporal coefficients are calculated at each grid node for each vertical mode $\boldsymbol{\beta}_{t i}=\boldsymbol{x}_{t}{ }_{t} \boldsymbol{\psi}^{\mathrm{i}}$. The essential point is that $\boldsymbol{\beta}_{t i}$ is taken as initial horizontal fields, not the temperature and salinity anomalies, and $\boldsymbol{E}-$ the matrix of horizontal EOF of the temporal coefficients of EOF vertical modes is calculated for them.

At the last stage, for each $\boldsymbol{\beta}_{t i}$ field temporal coefficients for all horizontal EOF modes are calculated

$$
\alpha_{t i}=\boldsymbol{\beta}_{t i} \boldsymbol{e}^{\mathrm{i}}
$$

and, using two inverse procedures, vertical profiles in each computational node are reconstructed:

$$
\begin{aligned}
\boldsymbol{\beta}_{t i} & \approx \sum_{i=1}^{M} \hat{\alpha}_{t i} \boldsymbol{e}^{\mathrm{i}}, \\
\boldsymbol{x}_{t}{ }_{t} & \approx \sum_{i=1}^{L} \hat{\beta}_{t i} \boldsymbol{\psi}^{\mathrm{i}},
\end{aligned}
$$

where $M$ is a number of horizontal modes; $L$ is a number of vertical modes [23, p. 97].

The modified method provided better coordination between the horizontal and vertical structure of the fields and reduction of the number of gross errors. Despite some complexity of the general calculation scheme (the presence of two different sets of modes and their conjugation), the numerical implementation of the algorithm became more efficient. Reduction of the computation time allowed us to carry out a great number of numerical experiments to select the optimal number of vertical and horizontal modes.

The spectra of EOF eigenvalues showed that the first 10 modes provide $98 \%$ of the total dispersion for vertical EOF and up to $60 \%$ for horizontal EOF of the vertical mode temporal coefficients. According to the results of a series of numerical calculations, it was decided to confine final calculation to five vertical EOF modes and five horizontal modes of the vertical EOF mode temporal coefficients. This combination gives minimal deviation from the optimal interpolation basic array with a significant reduction in the number of errors and a considerable saving of computation time.

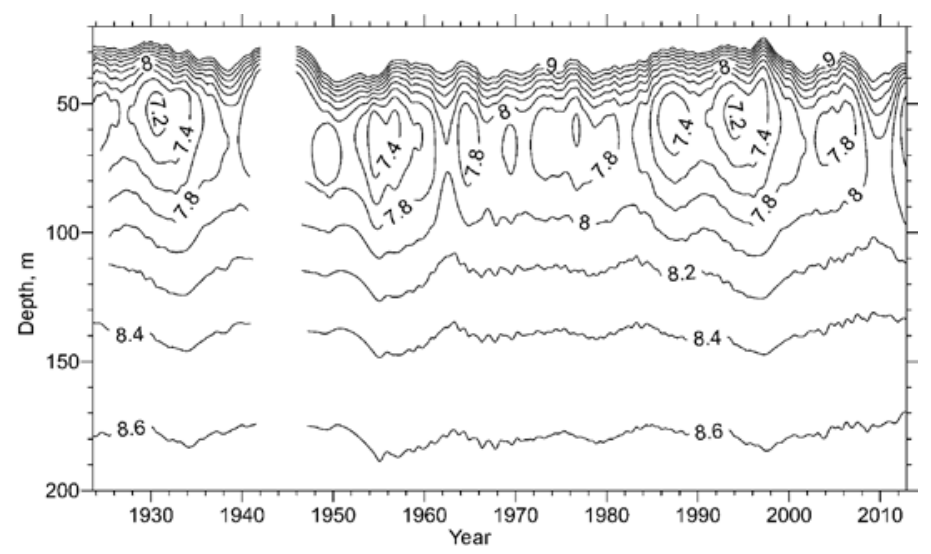

Fig. 3. Multi-year variations of the Black Sea water temperature in 20-200 m layer, the isotherms exceeding $9{ }^{\circ} \mathrm{C}$ are not shown 
As a result, the reanalysis array of monthly average thermohaline fields for the 1922-2015 period was calculated, the number of omissions made up $13 \%$. Horizontal spatial distribution of the array is $10^{\prime} \times 15^{\prime}$ (latitudinal $-18.5 \mathrm{~km}$ and longitudinal - 19-21 km), vertical one - 67 horizons (in 0-100 m layer - every $5 \mathrm{~m}$, then the step varies from 10 to $200 \mathrm{~m}$ ). After filtering the spikes by statistical criteria, about $20 \%$ of the array values were rejected.

The reconstruction of a continuous series of monthly average hydrological fields for the entire observation period in the Black Sea (since 1890) using this method is not possible. For adequate field reconstruction throughout the sea area the measurement data from multiple representative areas of the sea are required.

Later on, the reanalysis array was applied to study various aspects of the interannual and multi-year variability of the Black Sea thermohaline structure (Fig. 3, 4), density stratification, geostrophic circulation, etc. [26, 27].

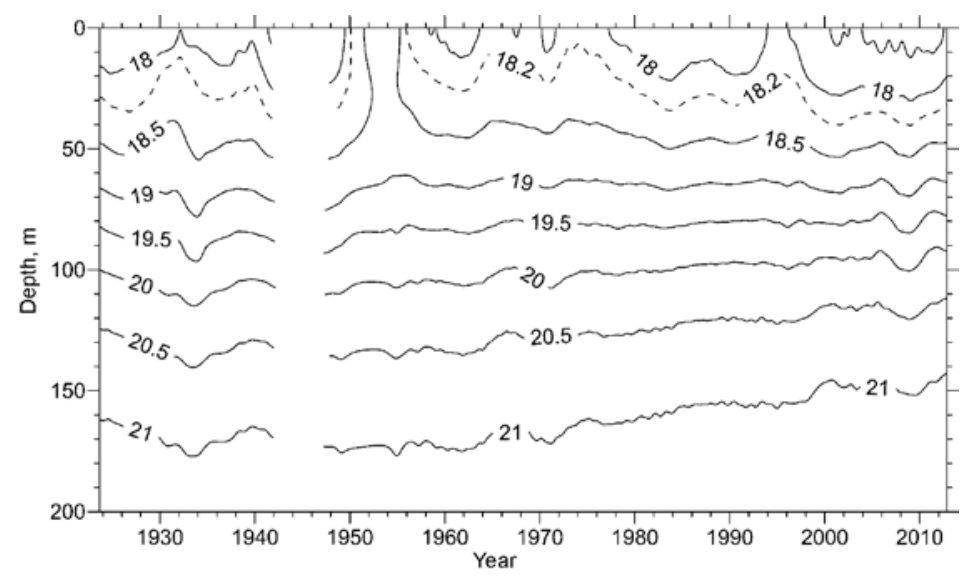

Fig. 4. Multi-year variations of the Black Sea water salinity in 20-200 m layer

Climatic arrays. In order to calculate the climatic fields of temperature and salinity, several methods were used. The simplest and most obvious is the arithmetic averaging of the reanalysis array data at the regular grid nodes for each month. The second method consists in the approximation of averaged values of reanalysis array or optimal interpolation array by annual and semiannual harmonics. The third method is based on the above-described algorithm of thermohaline field reanalysis with fundamental difference in the fact that vertical and horizontal EOF are calculated not by inter-annual anomalies, but by seasonal ones.

Comparison of climatic arrays calculated by different methods showed that when the main features of the field spatial structure coincide, there are regional differences in intra-annual evolution of thermohaline characteristics, especially in salinity. Nevertheless, spatial distribution of the hydrological seasonal cycle amplitude-phase characteristics retains its general regularities not only for different arrays, but also for different ten-year periods.

One of the characteristic features of the seasonal temperature cycle is a decrease in annual harmonic phase with an increase in the seasonal amplitude. Seasonal variation amplitude increased after 1980s and by now it reaches its maximum values (Fig. 5). 

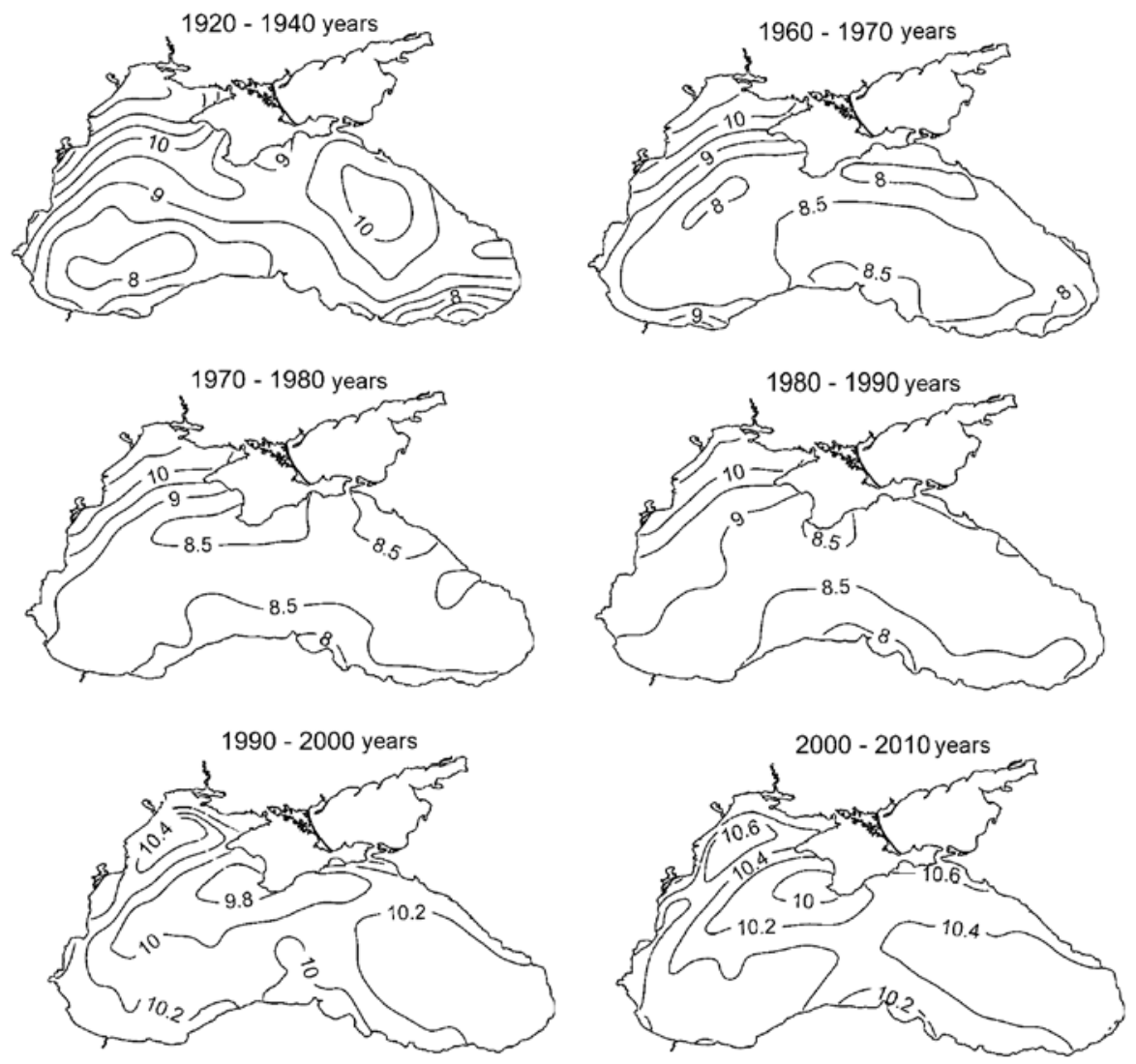

Fig. 5. Spatial distribution of the annual harmonic amplitude of the water temperature seasonal variations on the sea surface $\left({ }^{\circ} \mathrm{C}\right)$ for various ten-year periods

An increase in the seasonal amplitude of salinity occurs during the periods of general desalination of the sea. The main regularity of multi-year variations in the amplitude-phase characteristics of salinity is a positive correlation of phase and amplitude of the seasonal variation, which is the opposite of the changes in the water temperature seasonal variation.

Conclusions. Application of a new method for reconstructing the thermohaline fields of the basin according to irregular sets of observational data, combining optimal interpolation and decomposition into EOF functions, provided the calculation of the Black Sea hydrological structure reanalysis array for a long 1923-2015 period and climate fields for separated ten-year periods. Taking into account the significant omissions of observations in some years and the adopted criteria for filtering the errors of calculation results, relative portion of complete reconstruction cases of monthly average fields was about $70 \%$ of the studied period.

The comparison of climatic fields for separated ten-year periods showed that seasonal hydrologic cycle in the Black Sea remains sustainable during the entire $\mathrm{XX}$ century, spatial distribution of seasonal variability characteristics retains its 
general regularities for different ten-year periods. General trends of multi-year variations of amplitude-phase characteristics for temperature and salinity are different. With an increase in the water temperature seasonal variation amplitude, annual harmonic phase decreases, while the salinity is characterized by an inverse dependence.

In the future, this array of thermohaline field reanalysis can be used as a basis for more detailed study of the Black Sea long-term variability, and also can be applied in assimilating the observational data in the hydrophysical field reconstruction using hydrodynamic models.

\section{REFERENCES}

1. Knysh, V.V., Korotaev, G.K., Moiseenko, V.A., Kubryakov, A.I., Belokopytov, V.N. and Inyushina, N.V., 2011. Seasonal and Interannual Variability of Black Sea Hydrophysical Fields Reconstructed from 1971-1993 Reanalysis Data. Izvestiya, Atmospheric and Oceanic Physics, [e-journal] 47(3), pp. 399-411. https://doi.org/10.1134/S000143381103008X

2. Dorofeev, V.L., Korotaev, G.K. and Sukhikh, L.I., 2013. Study of Long-Term Variations in the Black Sea Fields Using an Interdisciplinary Physical and Biogeochemical Model. Izvestiya, Atmospheric and Oceanic Physics, [e-journal] 49(6), pp. 622-631. https://doi.org/10.1134/S0001433813060054

3. Mizyuk, A.I., 2014. Reanaliz Gidrofizicheskikh Poley Chernogo Morya na Osnove Assimilyatsii Dannykh Izmereniy Temperatury i Solenosti v Z-Koordinatnoy Modeli [Reanalysis of the Black Sea Hydrophysical Fields Based on Temperature and Salinity Measurement Data Assimilation in the z-Coordinate Model]. Morskoy Gidrofizicheskiy Zhurnal, (3), pp. 30-47 (in Russian).

4. Korotaev, G.K., Sarkisyan, A.S., Knysh, V.V. and Lishaev, P.N., 2016. Reanalysis of Seasonal and Interannual Variability of Black Sea Fields for 1993-2012. Izvestiya, Atmospheric and Oceanic Physics, [e-journal] 52(4), pp. 418-430. https://doi.org/10.1134/S0001433816040071

5. Gandin, L.S., 1965. Objective Analysis of Meteorological Fields. Jerusalem: Israel Program for Scientific Translations, 242 p.

6. Belyaev, V.I. and Timchenko, I.E., 1972. O Primenenii ob’ektivnogo i Chetyrekhmernogo Analiza v Okeanografii [On the Use of the Objective and Four-Dimensional Analysis in Oceanography]. In: MHI, 1972. Morskie Gidrofizicheskie Issledovaniya [Marine Hydrophysical Research]. Sevastopol: MHI. Iss. 2, pp. 80-92 (in Russian).

7. Nelepo, B.A. and Timchenko, I.E., 1978. Sistemnye Printsipy Analiza Nablyudeniy v Okeane [System Principles of the Analysis of Observations in the Ocean]. Kiev: Naukova dumka, 222 p. (in Russian).

8. Timchenko, I.E., Yarin, V.D., Vasechkina, E.F. and Igumnova, E.M., 1996. Sistemnyy Analiz Morskoy Sredy [Marine Environment Systems Analysis]. Sevastopol: MHI, 225 p. (in Russian).

9. Reynolds, R.W., Rayner, N.A., Smith, T.M., Stokes, D.C. and Wang, W., 2002. An Improved In Situ and Satellite SST Analysis for Climate. Journal of Climate, [e-journal] 15(13), pp. 1609-1625. https://doi.org/10.1175/1520-0442(2002)015<1609:AIISAS>2.0.CO;2

10. Kaplan, A., Cane, M.A., Kushnir, Y., Clement, A.C., Blumenthal, M.B. and Rajagopalan, B., 1998. Analyses of Global Sea Surface Temperature 1856-1991. Journal of Geophysical Research, [e-journal] 103(C9), pp. 18567-18589. doi:10.1029/97JC01736

11. Beckers, J.M. and Rixen, M., 2003. EOF Calculations and Data Filling from Incomplete Oceanographic Datasets. Journal of Atmospheric and Oceanic Technology, [e-journal] 20(12), pp. 1839-1856. doi:10.1175/1520-0426(2003)020<1839:ECADFF>2.0.CO;2 
12. Rayner, N.A., Parker, D.E., Horton, E.B., Folland, C.K., Alexander, L.V., Rowell, D.P., Kent, E.C. and Kaplan, A., 2003. Global Analyses of Sea Surface Temperature, Sea Ice, and Night Marine Air Temperature Since the Late Nineteenth Century. Journal of Geophysical Research, [e-journal] 108(D14), 4407. doi:10.1029/2002JD002670

13. Rayner, N.A., Brohan, P., Parker, D.E., Folland, C.K., Kennedy, J.J., Vanicek, M., Ansell, T.J. and Tett, S.F., 2006. Improved Analyses of Changes and Uncertainties in Sea Surface Temperature Measured In Situ since the Mid-Nineteenth Century: The HadSST2 Dataset. Journal of Climate, [e-journal] 19(3), pp. 446-469. https://doi.org/10.1175/JCLI3637.1

14. Kaplan, A., Kushnir, Y. and Cane, M.A., 2000. Reduced Space Optimal Interpolation of Historical Marine Sea Level Pressure: 1854-1992. Journal of Climate, [e-journal] 13(16), pp. 2987-3002. doi:10.1175/1520-0442(2000)013<2987:RSOIOH>2.0.CO;2

15. Alvera-Azcárate, A., Barth, A., Beckers, J.-M. and Weisberg, R.H., 2007. Multivariate Reconstruction of Missing Data in Sea Surface Temperature, Chlorophyll, and Wind Satellite Fields. Journal of Geophysical Research, [e-journal] 112(C3), C03008. doi:10.1029/2006JC003660

16. Alvera-Azcárate, A., Barth, A., Rixen, M. and Beckers, J.M., 2005. Reconstruction of Incomplete Oceanographic Data Sets Using Empirical Orthogonal Functions: Application to the Adriatic Sea Surface Temperature. Ocean Modelling, [e-journal] 9(4), pp. 325-346. doi:10.1016/j.ocemod.2004.08.001

17. Smith, T.M. and Reynolds, R.W., 1998. A High-Resolution Global Sea Surface Temperature Climatology for the 1961-90 Base Period. Journal of Climate, [e-journal] 11(12), pp. 33203323. doi:10.1175/1520-0442(1998)011<3320:AHRGSS >2.0.CO;2

18. Alvera-Azcárate, A., Barth, A., Sirjacobs, D. and Beckers, J.-M., 2009. Enhancing Temporal Correlations in EOF Expansions for the Reconstruction of Missing Data Using DINEOF. Ocean Science, [e-journal] 5(4), pp. 475-485. doi:10.5194/os-5-475-2009

19. Rixen, M., Beckers, J.M., Brankart, J.-M. and Brasseur, P., 2000. A Numerically Efficient Data Analysis Method with Error Map Generation. Ocean Modelling, [e-journal] 2(1-2), pp. 45-60. doi:10.1016/S1463-5003(00)00009-3

20. Ivanov, V.A. and Belokopytov, V.N., 2013. Oceanography of the Black Sea. Sevastopol: ECOSI-Gidrofizika, $210 \quad$ p. Available at: https://www.researchgate.net/publication/236853664_Ivanov_VA_Belokopytov_VN_Oceano graphy_of_the_Black_Sea_National_Academy_of_Sciences_of_Ukraine_Marine_Hydrophys ical_Institute_Sevastopol_210_p [Accessed: 06.09.2018].

21. Grigor'ev, A.V., Ivanov, V.A. and Kapustina, N.A., 1996. Correlation Structure of the Black Sea Thermohaline Fields in the Summer Season. Oceanology, 36(3), pp. 334-339.

22. Polonskii, A.B. and Shokurova, I.G., 2008. Statistical Structure of the Large-Scale Fields of Temperature and Salinity in the Black Sea. Physical Oceanography, [e-journal] 18(1), pp 3851. https://doi.org/10.1007/s11110-008-9008-4

23. Belokopytov, V.N., 2012. O Metode Vosstanovleniya Termokhalinnoy Struktury Chernogo Morya na Osnove Empiricheskikh Ortogonal'nykh Funktsiy [On the Method for the Black Sea Thermohaline Structure Reconstruction on the Basis of Empirical Orthogonal Functions]. In: MHI, 2012. Sistemy Kontrolya Okruzhayushchey Sredy [Monitoring Systems of Environment]. Sevastopol: MHI. Iss. 17, pp. $94-99$ (in Russian).

24. Belokopytov, V.N., 2013. Metod Rascheta Sezonnogo Tsikla Termokhalinnykh Poley na Osnove EOF-Razlozheniya [Method for Calculating the Seasonal Cycle of Thermohaline Fields Based on the EOF Decomposition]. In: MHI, 2013. Sistemy Kontrolya Okruzhayushchey Sredy [Monitoring Systems of Environment]. Sevastopol: MHI. Iss. 19, pp.116-121 (in Russian).

25. Belokopytov, V.N., 2017. Klimaticheskie Izmeneniya Gidrologicheskogo Rezhima Chernogo Morya [Climatic Changes in the Hydrological Regime of the Black Sea: Synopsis of a Doctoral Thesis, (Geogr.): 25.00.28]. Sevastopol, 42 p. (in Russian). 
26. Belokopytov, V.N., 2011. Interannual Variations of the Renewal of Waters of the Cold Intermediate Layer in the Black Sea for the Last Decades. Physical Oceanography, [e-journal] 20(5), pp. 347-355. https://doi.org/10.1007/s11110-011-9090-x

27. Belokopytov, V.N., 2013. Klimaticheskie Izmeneniya Gidrologicheskogo Rezhima Chernogo Morya [On the Climatic Variability of the Black Sea Thermohaline Structure]. In: Ekologicheskaya Bezopasnost' Pribrezhnoy i Shel'fovoy Zon i Kompleksnoe Ispol'zovanie Resursov Shel'fa [Ecological Safety of Coastal and Shelf Zones and Comprehensive Use of Shelf Resources]. Sevastopol: MHI NANU. Iss. 27, pp. 226-230 (in Russian).

About the author:

Vladimir N. Belokopytov - Head of Oceanography Department, FSBSI MHI (2 Kapitanskaya Str., Sevastopol, 299011, Russian Federation), Dr.Sci (Geogr.), ORCID ID: 0000-0003-4699-9588, Scopus Author ID: 6602381894, v.belokopytov@gmail.com

The author has read and approved the final manuscript.

The author declares that he has no conflict of interest. 